\title{
Bulk modulus of vegetable oil-diesel fuel blends
}

\author{
K. S. Varde \\ The University of Michigan-Dearborn, Dearborn, MI 48128, USA \\ (Received 13 December 1981; revised 21 April 1983)
}

\begin{abstract}
Bulk moduli of fuel blends containing different concentrations of vegetable oil and diesel have been measured at three different fuel temperatures. Presence of vegetable oil in the mixture increases the bulk modulus over that for the straight diesel fuel. For a given fuel pressure and fuel temperature, bulk modulus of the blend increases as the concentration of the vegetable oil in the blend increases. Increase in fuel temperature lowers the values of bulk moduli at all fuel pressures.
\end{abstract}

(Keywords: oil; diesel; blends)

The long-term threat of potential shortages or inordinate price increases for middle distillate petroleum fuels has provided some incentive to consider vegetable oils as fuel for compression ignition engines. Short-term engine tests indicate that vegetable oils can be used in compression ignition engines, either straight or in blends with diesel fuel. It has been shown that short-term engine performance is not greatly affected when vegetable oils are used as fuel ${ }^{1-3}$. However, long-term use of straight vegetable oils or in blends with small quantities of diesel fuel has shown some adverse effects on the engine power output, emissions and durability ${ }^{4-6}$.

Due to higher compression ratio, compression ignition engines have higher thermal efficiency than spark ignition engines and it is expected that future generation of direct injection type diesel engines would show at least $10 \%$ gain in thermal efficiency over the indirect injection type diesel engines ${ }^{7}$. The performance of a direct injection type compression ignition engine is highly dependent on the properties of fuel and by the manner in which the fuel is introduced in the combustion chamber. This, in turn, strongly depends on the fuel spray characteristics and how well they are matched with the aerothermodynamic conditions in the chamber.

If vegetable oil is to be significant as one of the future fuels for compression ignition engines it would be necessary to modify fuel injection equipment and combustion chamber design. These changes would be needed to take into account the effects of properties of vegetable oils on the spray characteristics and the subsequent process.

Some of the properties of vegetable oils which influence engine performance, have been investigated thoroughly ${ }^{8-10}$ but there is very little information on the bulk modulus of vegetable oils, either stright or in blends with diesel fuel. Bulk modulus is an important parameter that is used in fuel injection system modelling, analysis and design. The injection pressure and its variation during the injection period depends, among other factors, on the values of the bulk modulus of the fuel. For a given fuel injection system, changes in the bulk modulus will alter fuel spray characteristics which may result in inefficient engine performance. The lack of sufficient information on the bulk modulus would make the design and analysis of fuel injection system for vegetable oils and their blends more difficult.

Because of this need, bulk moduli for various blends were measured in the laboratory at fuel pressures as high as $150 \mathrm{MPa}$ and the temperature range of $5-45^{\circ} \mathrm{C}$.

\section{EXPERIMENTAL}

The bulk modulus of fuel was measured by using $\mathrm{P}-\mathrm{V}-\mathrm{T}$ method $^{11}$. A specially designed apparatus consisting of a leakproof cylinder and plunger was used to compress the fuel; the plunger was driven by a fast acting hydraulic ram. The details of the apparatus have been described elsewhere ${ }^{2}$. In the current study, the cooling and the heating arrangements were modified to maintain a better control of the fuel temperature. The compression rate of the test fuel was limited to about $600 \mathrm{MPa} \mathrm{s}^{-1}$, which is lower than generally found in diesel fuel injection systems. Some experiments carried out at lower compression rates for straight diesel fuel indicated the effect of compression rate on the bulk modulus to be of secondary importance compared to the fuel temperature and pressure effects ${ }^{12}$. The pressure generated during fuel compression was measured by a calibrated Kistler pressure transducer. Blends of diesel fuel No. 2 (cetane number 44 46) and degummed, refined, soybean oil were used to test fuels. The volume percentage of soybean oil in the test blends were: $0,20,50,80$ and 100 . The blends were allowed to stand for at least two days before the experiment and were periodically tested for their consistency. The density and viscosity of the blends were measured in the laboratory and are shown in Table 1.

The experiments were carried out at three different temperatures: $5,25,45^{\circ} \mathrm{C}$. Before each experiment the apparatus with the test fuel was allowed to attain the desired temperature for at least a day in a temperaturecontrolled chamber. Special precautions were taken to remove any trapped air from the fuel compression chamber but no air from the fuel was removed. Either warm or cold air was blown on the apparatus to maintain fuel temperature at a constant level during fuel compression process. The temperature was monitored by a highly sensitive probe. The maximum temperature increase was 
found to be $\approx 1^{\circ} \mathrm{C}$. Thus, the measurement of bulk modulus was almost at isothermal conditions.

\section{RESULTS AND DISCUSSION}

Figures $I$ and 2 show the variation of isothermal bulk modulus for all the fuels tested in the study. The bulk modulus is found to increase with fuel pressure but the rate of increase in the bulk modulus appears to decrease at high fuel pressures. The results shown for straight diesel No. 2 are in general qualitative agreement with those of an earlier study ${ }^{13}$ carried out up to a fuel pressure of $50 \mathrm{MPa}$.

For a given fuel temperature, bulk modulus increases with the concentration of vegetable oil in the blend. However, at low fuel pressures, the absolute difference in the values of the bulk moduli between the various blends and straight vegetable oil is small. It is interesting to note that even a small concentration $(20 \%)$ of vegetable oil in the mixture alters the values of the bulk moduli appreciably. Presence of vegetable oil shifts the curves for the variation of bulk modulus with pressure closer together, as shown by Figure 2.

At low fuel pressure, the liquid molecules fit loosely together with considerable free space between them. As the liquid is compressed the free space decreases rapidly at lower pressures. At high pressure where the free-space is almost totally removed, further decrease in volume is

Table 1

\begin{tabular}{rll}
\hline $\begin{array}{l}\text { Vegetable oil in } \\
\text { blend (\%) }\end{array}$ & $\begin{array}{l}\text { Density at } 20^{\circ} \mathrm{C} \\
\left(\mathrm{kg} \mathrm{m}^{-3}\right)\end{array}$ & $\begin{array}{l}\text { Viscosity at } \\
20 \mathrm{C}\left(\mathrm{mN} \mathrm{s} \mathrm{m}^{-2}\right)\end{array}$ \\
\hline 0 & 825 & 2.9 \\
20 & 841.3 & 6.66 \\
50 & 865.6 & 14.0 \\
80 & 890.1 & 38.6 \\
100 & 906.0 & 72.3 \\
\hline
\end{tabular}

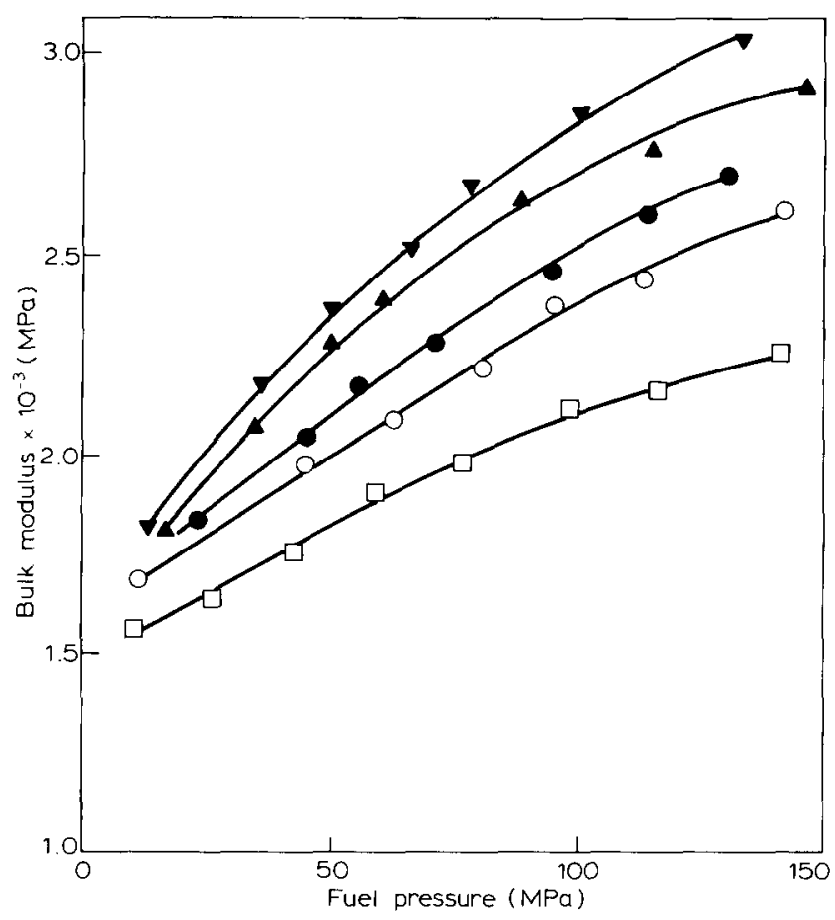

Figure 1 Variation of bulk modulus with fuel pressure. Fuel temperature, $5^{\circ} \mathrm{C}$; vegetable oil in mixture: $\square, 0 \% ; 0,20 \%$; $50 \% ; \triangle 180 \% ; \nabla, 100 \%$

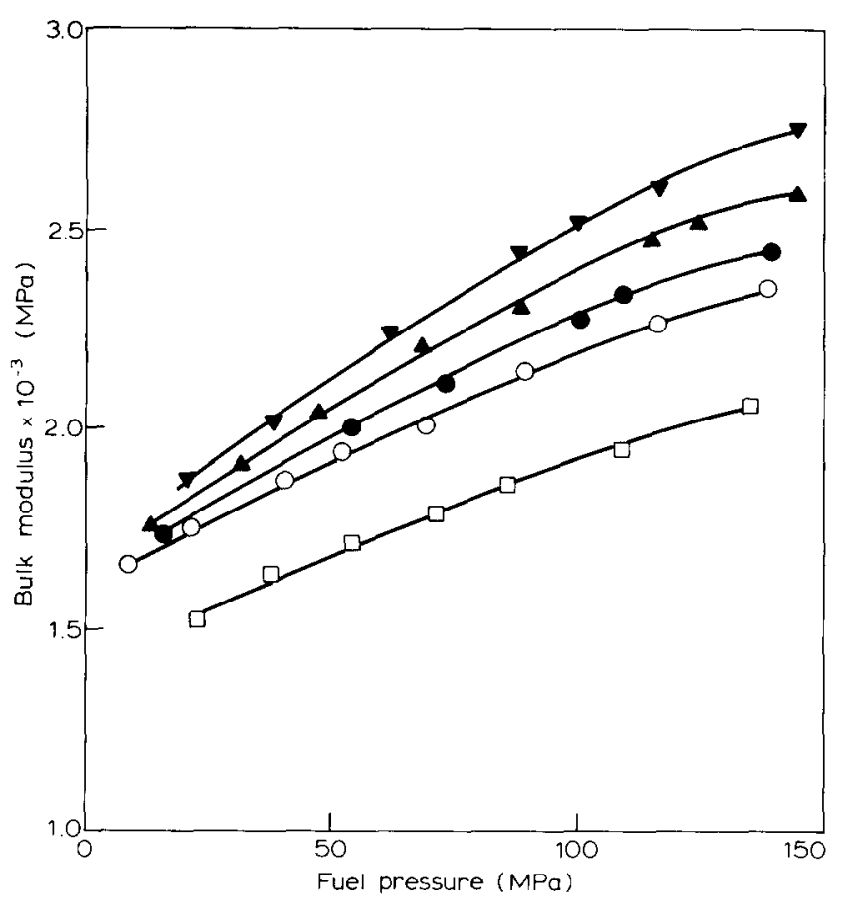

Figure 2 Variation of bulk modulus with fuel pressure. Fuel temperature, $25^{\circ} \mathrm{C}$; vegetable oil in mixture: $\square, 0 \%$; $0,20 \%$; ○. $50 \% ; \Delta, 80 \% ; \nabla, 100 \%$

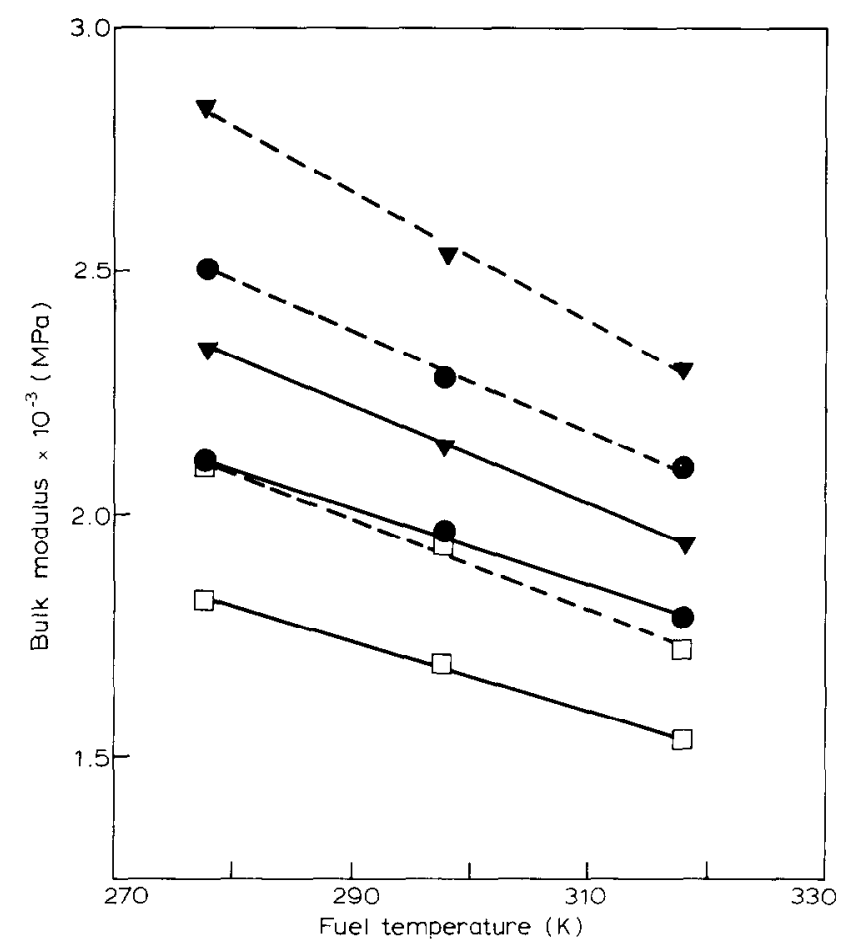

Figure 3 Effect of fuel temperature on the bulk modulus. Fuel pressure: ——, $50 \mathrm{MPa}$; - - , $100 \mathrm{MPa}$; vegetable oil in mixture: $\square, 0 \% ;, 50 \% ; \nabla, 100 \%$

believed to be associated with the molecules themselves once they are nearly in contact with the neighbouring molecules. This behaviour results in an increase in the bulk modulus with fuel pressure. The behaviour of fuel blends at high pressures is more complicated due to interactions in the mixture. Using the hypothesis of Richards and Chadwell ${ }^{14}$, addition of diesel fuel to vegetable oil changes the overall equilibrium distribution between the different molecules. The theoretical value of 
the bulk modulus is very sensitive to small change in the distribution function, particularly at small distances from the central molecule ${ }^{15}$.

As dicsel and vegetable oil have different bulk moduli, a change in the relative number of molecules will be accompanied by a change in the bulk modulus. As shown in Figure 2, replacing diesel fuel No. 2 by straight vegetable oil at $25^{\circ} \mathrm{C}$ will increase fuel bulk modulus by $\approx 30 \%$ at $100 \mathrm{MPa}$. Thus, a fuel injection system designed to handle diesel fuel will generate different injection pressures when used with straight vegetable oil. This will alter fuel spray characteristics therby affecting engine performance.

Figure 3 shows the effect of temperature on the bulk modulus, at two different fuel pressures, 50 and $100 \mathrm{MPa}$, respectively. Bulk moduli of all the blends decreased as the fuel temperature increased. As temperature increases, collisions between the molecules become more vigorous and, because the molecules are not completely rigid, their effective volume decreases. The decrease in the effective volume of a fuel blend depends on the relative concentrations of the diesel and the vegetable oil molecules. This phenomenon is responsible for lowering bulk modulus with temperature increase.

These variations in the values of the bulk moduli may have to be included in analysing and designing a highpressure fuel injection system for optimum engine performance.

\section{CONCLUSIONS}

Presence of vegetable oil in diesel fuel blends increases the values of bulk moduli at all the fuel temperatures. Bulk moduli of straight vegetable oil and its blends increases with fuel pressure. At low pressures, the absolute differences in the bulk moduli for straight vegetable oil and the blends are small.

\section{REFERENCES}

1 Barsic, N. J. and Humke, A. I. SAF Paper No. 810262, Soc. Auto Engg., PA, USA, 1981

2 Forgiel, R. and Varde, K. S. SAE Paper No. 811214, Soc. Auto Engg., PA, USA, 1981

3 Seddon, R. H. Gas Oil Power 1942, 8, 135

4 Baranescu, R. A. and Lusco, J. J. Proc. Int. Conf. Vegetable Oils, ASME, 1982 (August), pp $312-328$

5 Ziejewski, M. and Kaufman, K. R. SAE Paper 820257 , Soc. Auto Engg., PA, USA, 1982

6 Quick, G. R. ASAE Paper No. 80-1525, 1980

7 Monaghan, M. L. Paper presented at the Int. Energy Agency Conf., Berlin, W. Germany, 1981

8 Tahir, A. R., Lapp, H. M. and Buchanan, L. C. Proc. Int. Conf. Vegetable Oils, ASAE, 1982 (August), pp 82-91

9 Ryan, T. W., Callahan, T. J. and Dodge, L. G. Proc. Int. Conf. Vegetable Oils, ASME, 1982 (August), pp 70-81

10 Goering, C. E., Schwab, A. W., Daugherty, M. J., Pryde, E. H. and Heakin, A. J. ASAE Paper No. 81-7019, 1981

Peeler, R. L. and Green, J. ASTM Bulletin 1959, 21, 51

Varde, K. S., Can. J. Chem. Eng. 1982, 60(5), 710

Talbot. A. C. London Phil. Mag. 1935, 19, 1126

Richards, T. W. and Chadwell, H. M. J. Am. Chem. Soc. 1925, 47, 2283

15 Temperley, H. and Trevena, D. H. 'Liquids and Their Properties' Ellis Horwood Publisher, 1978, pp 149-162 